describing the data, TPB may not be an appropriate theory to apply to the prediction of sports safety behaviour.

\title{
0112 CAN THE THEORY OF PLANNED BEHAVIOUR PREDICT COACH INTENTIONS TO IMPLEMENT A SAFE LANDING PROGRAM DURING NETBALL TRAINING SESSIONS?
}

P White*, S Ullah, M Romiti, C Finch Correspondence: School of Human Movement and Sport Sciencts, University of Ballarat, PO Box 663, Ballarat 3353, Australia

10.1136/ip.2010.029215.112

Introduction It is currently unknown whether the Theory of Planned Behaviour (TPB) can predict intentions to engage in sports safety behaviours and what particular TPB constructs are important in this prediction. The purpose of this study was to determine whether TPB can predict coach intentions to teach correct landing technique to junior players and what particular constructs are most important in this prediction.

Methods Fifty-one coaches completed a 12 -item survey to measure their attitudes, subjective norm and perceived behavioural control around the behaviour of teaching correct landing technique during junior netball training. Coaches were also asked about their intention to teach correct landing technique at netball training sessions. Factor analysis was used to identify the factors in relation to the TPB. Structural equation modelling was used to determine whether TPB could be used to predict the intention to teach correct landing technique.

Results The factor analysis identified that the three factors were sufficient to describe the 12 statements. These three factors were consistent with the attitudes, subjective norm and perceived behavioural control dimensions of the TPB, explaining $21 \%, 19 \%$ and $14 \%$ of the total variability respectively. Structural equation modelling revealed that none of the TPB factors were significant predictors to explain the intention of teaching correct landing technique.

Conclusions Although the three factors attitudes, subjective norm and perceived behavioural control were sufficient for 